\title{
LETTER
}

\section{Human factors play a vital role in the outcome of percutaneous dilatational tracheostomy}

\author{
Stephen JM Sollid ${ }^{1 *}$ and Eldar Søreide ${ }^{2}$ \\ See related research by Simon et al., http://ccforum.com/content/17/5/R258
}

In a recent issue of Critical Care, we read with great interest the report by Simon and colleagues [1] on fatal complications of percutaneous dilatational tracheostomy (PDT). We agree with the authors' suggestions for improving the safety of this procedure, but we think these improvements cover only part of the picture. We have previously concluded that PDT is a high-risk procedure [2]. This led us to perform a risk assessment of PDT in the ICU, where we found that several non-technical factors also influence the outcome of PDT [3]. In our risk assessment, we focused on the same two complications that Simon and colleagues identified as the most common: bleeding and airway complications. Similar to the findings by Simon and colleagues, our findings identified technical causes for the complications, but these technical causes were influenced by several non-technical factors (risk-influencing factors), like operator experience, culture and attitudes of the team, and protocol quality.

Given that $70 \%$ of errors in medicine are caused by human factors or non-technical causes [4], we believe it is important to stress the influence of non-technical factors when trying to improve performance and outcome of PDT in the ICU. As we postulated in our risk assessment, improving non-technical risk-influencing factors may reduce the incidence of bleeding complications by a factor of five. We think these factors should be taken into account in the same manner as the measures suggested by Simon and colleagues when trying to improve the safety of PDT in the ICU.

\section{Abbreviations}

PDT: Percutaneous dilatational tracheostomy.

\section{Competing interests}

The authors declare that they have no competing interests.

\section{Author details}

'Department of Health Sciences, University of Stavanger, 4036 Stavanger, Norway. ${ }^{2}$ Department of Anaesthesiology and Critical care, Stavanger University Hospital, Postal Box 8100, 4068 Stavanger, Norway.

Published: 21 Feb 2014

\section{References}

1. Simon M, Metschke M, Braune SA, Puschel K, Kluge S: Death after percutaneous dilatational tracheostomy: a systematic review and analysis of risk factors. Crit Care 2013, 17:R258.

2. Sollid SJ, Strand K, Søreide E: Percutanous dilatational tracheotomy in the ICU: a Norwegian survey focusing on perceived risk and safety attitudes. Eur J Anaesthesiol 2008, 25:925-932.

3. Sollid SJ, Eidesen K, Aven T, Søreide E: Assessing the risk of percutaneous dilatational tracheostomy in ICUs using a broad event-consequenceuncertainty perspective. Int J Risk Saf Med 2010, 22:115-129.

4. Kohn LT, Corrigan J, Donaldson MS, Institute of Medicine (US), Committee on Quality of Health Care in America: To Err is Human: Building a Safer Health System. Washington, DC: National Academy Press; 2000.

$10.1186 / \mathrm{cc} 13739$

Cite this article as: Sollid and Søreide: Human factors play a vital role in the outcome of percutaneous dilatational tracheostomy. Critical Care 2014, 18:409

\footnotetext{
* Correspondence: stephen.j.sollid@uis.no

'Department of Health Sciences, University of Stavanger, 4036 Stavanger, Norway
} 